\title{
LA CRISIS MEDIOAMBIENTAL Y SU IMPACTO COMO EPISTEMOLOGÍA COMPLEJA
}

\author{
Taeli Raquel Gómez Francisco ${ }^{1}$
}

Recibido el 3 de septiembre de 2014, aprobado el 10 de febrero de 2015 y actualizado el 4 de mayo de 2015

DOI: 10.17151/luaz.2015.41.14

\section{RESUMEN}

Este trabajo tiene por objetivo demostrar que el actual estadio contradictorio de la relación sociedades-naturalezas también viene dado por la manera histórica que la Epistemología y los paradigmas científicos han producido. Lo anterior implica indagar históricamente para demostrar que ello tiene un origen delimitado, y, por lo tanto, lejos de naturalizarlo, es posible superarlo como paradigmas limitados históricamente. Y desde ahí comprender que los paradigmas científicos complejos actuales, exigidos por la cualidad y magnitud de una crisis ecosocial, aportan a las nuevas nociones de realidad, mayor integración, relación e interdependencia, lo cual favorece nuevas propuestas a la crisis medioambiental. Con ello, entonces, la Filosofía y la Epistemología, como espacios reflexivos, pueden dialogar como saberes relevantes, en la necesidad de convertir una expectativa ideal de sobrevivencia humana-no humana en esperanza de futuro.

\section{PALABRAS CLAVE}

Medio ambiente, crisis ambiental, paradigmas mecanicistas, complejidad, Epistemología.

\section{ENVIRONMENTAL CRISIS AND ITS IMPACT AS COMPLEX EPISTEMOLOGY}

\begin{abstract}
This work aims to demonstrate that the current adversarial stage of the relationship societies-natures is also being happening because of the historical way that Epistemology and scientific paradigms have produced. This implies to investigate historically to demonstrate that this has a delimited origin and therefore, far from naturalizing it, it is possible to overcome it as historically limited paradigms and from there to understand that current complex scientific paradigms, demanded by the quality and magnitude of an eco-social crisis, contribute to new notions of reality, a greater integration, relationship and interdependence, which encourages new proposals to the environmental crisis. Then, philosophy and epistemology, as reflective spaces can dialogue as relevant knowledge, on the need to transform a human-nonhuman ideal expectation of survival in hope for the future.
\end{abstract}




\section{KEY WORDS}

Environment, environmental crisis, mechanistic paradigms, complexity, epistemology.

\section{INTRODUCCIÓN}

En el informe de la UNICEF (2012), denominado "Mi hijo ya no come arena", se denuncia que alrededor de 6,9 millones de niños menores de 5 años mueren cada año por causas prevenibles, y que una tercera parte de estas muertes está relacionada con la desnutrición. Al mismo tiempo, el Informe Anual 2011, elaborado por el Programa de las Naciones Unidas para el Medio Ambiente (PNUMA), señala que el calentamiento global, la contaminación, la explotación de los recursos naturales, no tienen una proyección amable para la vida del Planeta. En consecuencia, el grado de importancia que asume hoy y la indivisibilidad de los problemas sociales y ecológicos, deviene crisis ecosocial. ${ }^{2}$ Esta realidad es inquisidora de cualquier actitud pasiva que puedan adoptar el pensamiento, el saber científico y la Filosofía, en especial, cuando se ha puesto en inminente riesgo la sobrevivencia de la especie y la vida del Planeta.

En tal sentido, la relación sociedades-naturalezas ${ }^{3}$ no solo está instalada en nuestra historia actual como una realidad contradictoria de amenaza planetaria y vital o, al menos, de nuestra especie, sino, al mismo tiempo, ha producido cambios a la noción de realidad y al cómo conocerla, lo que es fundamental para intervenirla. Por lo tanto, los cambios que en el saber científico se susciten afectan significativamente la visualización y comprensión del objeto a abarcar, tanto sus macro movimientos, como el hambre, la pobreza, la contaminante lluvia ácida y una acelerada disminución de la capa de ozono, o bien, como de los micro y localizados problemas de vulneración de derechos, la pérdida de biodiversidad del Amazonas, la disminución de bosque nativo y humedales.

De la valoración de dichas consideraciones nos surgen las siguientes interrogantes: ¿la relación sociedades-naturalezas y sus plurales acoplamientos han sido determinantes o han ejercido algún grado de influencia en la imagen de realidad y del cómo la conocemos?, ¿existe alguna ligazón o interdependencia entre ello, especialmente, entre la crisis ecosocial y los cambios epistemológicos?

Para abordar este trabajo nos enfocaremos en la relación sociedades-naturalezas, desde sus momentos primitivos hasta su estado de crisis ecosocial, para que, desde el saber omnicomprensivo de la Filosofía, se pueda identificar y comprender la indivisibilidad del proceso histórico y sus representaciones espirituales-gnoseológicas, abarcando desde la magia hasta el paradigma científico de la complejidad. Además de ser un requerimiento ético desde y para las Generaciones 
Futuras en el contexto de una crisis ecosocial que exige transformaciones más complejas.

\section{LA IMPORTANCIA DE LA RELACIÓN SOCIEDADES- NATURALEZAS, EN LA CONCEPCIÓN DE REALIDAD Y PARA LA TEORÍA DEL CONOCIMIENTO}

A pesar de proponer con el subtítulo una lectura histórica de la relación sociedades-naturalezas, lo iniciamos desde una inspiración actual, es decir, desde la crisis ecosocial. ${ }^{4}$

La presencia de una crisis ecosocial como un estadio contradictorio, representa un desafío histórico y epistemológico de sobrevivencia. En otros términos, queremos plantear la importancia que tienen las nociones de realidad -determinadas por las distintas prácticas históricas- para favorecer o no la relación sociedades-naturalezas. Como veremos, la incapacidad para visibilizar la crisis ecosocial como una unidad y, por el contrario, fragmentarla, ha estado instigada por modelos científicos reduccionistas provenientes de la concepción de un mundo divisible y simple, que venía con la metáfora de la máquina, lo cual derivó en distintas revoluciones científicas ${ }^{5}$. Afortunadamente, con aires de esperanza, la magnitud de la crisis convocó nuevos paradigmas científicos de tendencias más generales, como los complejos.

En consecuencia, para visibilizar esta importancia, haremos una revisión histórica. En razón de ello, demostraremos que no siempre los límites divisorios entre las naturalezas y sociedades han sido los mismos y han influido en las imágenes de la realidad de la misma forma; más bien, la tajante separación entre una y otra fue naturalizándose desde la modernidad con la ayuda de la racionalidad científica fraccionadora y el saber científico. Sin embargo, hoy resulta difícil afirmar fronteras entre lo natural y social; por el contrario, diremos que se encuentran condicionadas históricamente, y por lo tanto de ello depende nuestro conocimiento para intervenir de la manera que se requiere.

Para abordar lo anterior, proponemos una atención histórica primitiva, desde la antigua Grecia en adelante, como un momento importante para la formación de nuestro pensamiento occidental. Intentamos involucrar el supuesto ontológico presente en algunas épocas, al sujeto histórico cognoscente y tal actividad.

\section{a) Un modo de producción primitivo}

Un modo de producción primitivo se caracteriza por un nivel de inmediatez y por su unidad sincrética, donde no existen diferenciaciones y, menos aún, la existencia de un individuo como entidad sustantivada independiente de la Pachamama. Para las culturas antiguas la relación sociedades-naturalezas es muy distinta a la actual, pues los primitivos están más cerca de 
afirmarse inclusivamente con la naturaleza que con un otro de su misma especie; por ejemplo, con su Tótem mantienen un vínculo de parentesco más cercano que con un humano de otra tribu.

La relación sociedades-naturalezas se manifiesta a nivel de alianza y sobrevivencia como una relación de carácter inmanente a través de diálogos entre seres humanos-no humanos. Sin presuponer por ello un pensamiento abstracto y teórico, sino más bien, se actúa directamente sobre imágenes concretas (Donini, 1961, p. 191). Con un animismo, sobre concretos, como una planta con maná o poder otorgado a materiales orgánicos e inorgánicos.

Todo ello nos da cuenta de una forma de conocer en la inmanencia del animismo y la magia. ${ }^{6}$ En esta lógica, para el hombre primitivo, entre él y determinados objetos de la naturaleza "existen nexos ocultos, y que precisamente los mismos son los promotores del influjo pernicioso o benéfico de las cualidades sobrenaturales incorporadas en los objetos" (Burlatski et al., 1982, p. 190). Desde ahí es coherente sostener la posibilidad de influir mediante determinadas representaciones $y$ acciones sobre las personas, animales, vegetales $y$, en general, sobre los fenómenos de la naturaleza y la vida humana.

Decir que ellos no podían conocer y explicar la naturaleza, y que por tal razón recurrían a nociones mágicas sería una arrogancia cultural. Por el contrario, había una relación interna desde su práctica entre su noción de realidad, la forma de conocerla y su técnica de intervención. Así, por ejemplo, las pinturas rupestres que evidencian esta conexión íntima y no externa entre el humano-no humano, como la técnica animista de la caza, no tendrían sentido. ${ }^{7}$

\section{b) Sociedades griegas}

En las sociedades de clase, como la esclavista, se producen separaciones entre el campo y la ciudad, entre el trabajo manual e intelectual, lo que implica la emancipación de la idea de su soporte concreto y el saber filosófico.

No es casual, entonces, que en la necesidad de favorecer el comercio marítimo surja el logos, lo que favorece el encuentro entre los distintos pueblos, a pesar de sus diferencias; razón por la cual, se puede decir, que los primeros filósofos griegos estuvieran en los bordes marítimos como Miletos, y que, más aún, sus problemas filosóficos fueran la búsqueda de algo permanente, como el arjé.

Es en estas condiciones donde aparece la physis y la Filosofía como un saber que la favorece. Con tales elementos se le da unidad al cosmos. Ello es un aporte histórico que les vale a los griegos el inicio de su propuesta filosófica; en última instancia, la posibilidad de representar una realidad, en tanto atención a las esencias, como el $\mathrm{Nu}$ o masa líquida que propone Tales de Mileto, el apeiron Anaximandro, el aire Anaxímenes, el fuego Heráclito. Este comienzo filosófico tampoco distingue al hombre 
de la consideración cosmológica. Desde esta lógica, el propio hombre se explica indistintamente, y se concibe como un elemento integrante más; ni siquiera lo transforma en un problema filosófico específico: los mismos principios que explican la constitución del mundo, lo hacen de éste (Abbagnano, 1955, p. 11).

Entre todas las posiciones se establecen ciertas constantes que sincronizan el cómo concebir el ser de la realidad -como su lado más ontológico- y la forma de conocerla -como su propuesta gnoseológica-. Así, por ejemplo, los antiguos atomistas, Leucipo y Demócrito, señalan la composición de unos átomos, que mediante el orden y su posición no solo dan cuenta del ser, sino, además, del conocer. Esta correspondencia les era tan inmanente, que "la sensación nace de imágenes que las cosas producen en el alma mediante flujos o corrientes de átomos que emanan de ellas" (Abbagnano, 1955, p. 39). También podemos mencionar el razonamiento de los eleáticos, como Empédocles, para quien el conocimiento se produce por el encuentro entre el elemento que reside en el hombre y coincidiendo con el elemento- que está fuera de él, es decir, la conexión integrada se da por inseparabilidad hombre con el Universo. En definitiva, para que esto no sea absurdo en su época, debe haber coherencia entre el ser y conocer, y los supuestos y enfoques que lo permiten.

En general, el recorrido por la Filosofía griega nos da cuenta de que a pesar de todas las grandes diferencias, los problemas filosóficos unen la relación hombre-naturaleza y la Gnoseología. Platón, por ejemplo, enlaza su cosmología y antropología con el mundo de las ideas; la dualidad cuerpo alma y la anamnesis implica un conocer-reconocer, un hombre que antes de instalarse en su cuerpo estuvo en contacto con el ser verdadero. La perspectiva de la teoría del conocimiento aristotélica, contrariamente al idealismo objetivo de su maestro, reconoce la existencia de una realidad, más bien independiente del sujeto, donde las sustancias son descritas, en tanto, como pensamientos que explican sus cualidades y atributos, apoyándose con una identidad lógica y teleológica. También se encuentra el vínculo relacional de lo ontológico y lo gnoseológico en la filosofía epicúrea o estoica que vincula la concepción de naturaleza y las relaciones humanas a la Ética y Teoría del Conocimiento.

También podemos reconocer en los griegos una cierta relación entre la -su- sociedad y la naturaleza, en la cual no importa una diferenciación dualista ni jerarquizada de la primera; más bien, el logos o nous une ser y conocer en una trama cósmica y categorial, como lo hace la ética aristotélica o epicureísta. No incurrimos en imprecisiones cuando afirmamos que la desconexión de naturalezas y sociedades es una figura también- extraña para el mundo antiguo de los griegos; consecuentemente, creemos, que de igual modo se puede afirmar que la separación sujeto-objeto no tuvo cabida en otros contextos culturales, tan claramente como lo ha sido para el clásico moderno. 
La profundidad griega nos otorga información de cómo se relaciona el contexto histórico socio-natural con su objetivación filosófica en general, y su particular recepción en el momento gnoseológico. Así pues, en una primera etapa, la subjetividad presocrática no nos presenta un mundo con independencia del cosmos; de igual modo, tampoco prevalece un momento epistémico que represente una conciencia de la conciencia de otro. Ángel-Lara (2003, p. 7) señala que, "Para el presocrático pensar el ser, es aprehender el ser y no sólo a una mera forma de pensarlo. Esta es una determinación fundamental de orden epistemológico-ontológico [...]", por el contrario, en una polis activa, el sujeto, en tanto ser social y político, se inclina en desarrollar con más énfasis el nomos -lo convencional- que la physis; es decir, desde una subjetividad que da cuenta de sí. En definitiva, el desarrollo de las sociedades con sus naturalezas, no es un proceso que transcurre por una vía distinta al ser y cómo conocer-la.

Podemos decidir, al mismo tiempo, que el derrumbe de la polis fragilizó el referente social que le sirvió al griego para un cambio filosófico, provocando un mayor interés por la ética como una nueva etapa de la filosofía griega, y desde ellas nuevas bases para sus propuestas epistemológicas. Epicúreo encarna esta ilustración cuando plantea la composición de la realidad formada por átomos, pero que esta vez, a diferencia de los atomistas anteriores, incorpora el vacío para intervenir las causalidades y el destino, en pos de afirmar la libertad y negar el miedo para lograr la felicidad; con ello validan a los sentidos como fuente del conocimiento, dado que estos átomos nos producen una impresión sensorial penetrando en nuestros sentidos y creando una imagen o impresión, una copia exacta. La lógica estoica plantea también el conocimiento como condición de vivir correctamente, en el contexto de una relación con la naturaleza.

Hay que develar, además, como enseña Delgado (2002), la relación que entre los saberes se establece; él sostiene que en el pensamiento antiguo coexistía una mayor multiplicidad horizontal entre los distintos saberes. Con Aristóteles, se ejemplifica a través de la distinción entre el arte o técnica y la sabiduría como modos del saber. A diferencia de nuestra época, el saber instrumental que media entre el hombre y su relación de poder fue, incluso, el menos valorado de todos; esto último porque se asociaba a labores propias de los esclavos, a diferencia de un pensamiento relacionado con el hombre libre de la polis. Con el fin de la polis, esta diversidad se desplomó, y el cambio de paradigma del universo, del hombre, en el período helenístico, se amplió en lo físico y lo político-social.

El individuo antes protegido y constituido por la polis, quedó a expensas de su propia fragilidad y fue impulsado a la búsqueda de nuevos elementos integradores lo suficientemente espirituales y fuertes, como para garantizar la solución de las rupturas. 


\section{c) Sociedades feudales}

En el Medioevo cambian las relaciones socionaturales, y con ellas la imagen de mundo. Si para los griegos el movimiento demostraba la circularidad y lo cíclico de la naturaleza, donde a pesar de los cambios se mantiene una esencia, con las nuevas relaciones socio-políticas romanas y el cristianismo, se asumirá una cosmología que describe uno lineal, con un comienzo y un final, como lo plantea el sentido de Creación y su trascendencia. ${ }^{8}$ El animismo, sin embargo, perdura y obstaculiza plantear la dualidad sujeto-social versus naturaleza-objeto. Coincidimos con Ángel-Lara (2003, p. 4) cuando señala que "no hay un mero cambio de objeto, sino un cambio en el sujeto; cambio que se manifiesta como una transformación de los intereses de la reflexión".

La actividad socioproductiva, el ámbito de las prácticas agrícolas y ganaderas, expresada como cercanía de las sociedades con la tierra, influye en una conciencia social divinizada. Esta, está afectada por la relación interna que aún existe entre sociedad y naturaleza, la que se nos presenta como una imagen de perfección que se desprende de la misma ley eterna y natural, de la cual nos emerge la explicación de nuestro ser y saber. De alguna forma, hay una cierta cercanía -aún- entre hombrenaturaleza, pues como dice Barros, en ámbitos semánticos "El hombre medieval no se confunde con la naturaleza como en las sociedades primitivas, ni se le opone como en las sociedades modernas y contemporáneas, pero mantiene su no-diferenciación del medio natural" (Barros, 1997).

Con esto, se da paso a un saber trascendente y espiritualizado. Coexisten la fe y la razón -pero en un contexto religioso-, donde esta última no siempre puede conocer las verdades, pues en algunos casos representa un límite para ellas. No obstante, la lluminación y la Revelación producen una base no solo para el conocimiento, sino también para la técnica, como podrían ser los rezos, que requieren de la presencia de una voluntad que pueda ser modificada.

\section{d) Sociedades capitalistas}

Ahora bien, la formación económico-social capitalista cambia revolucionariamente la forma del trabajo y sus relaciones de apropiación. En este nuevo escenario histórico se altera la relación social y productiva, y, consecuentemente, la relación con la tierra. Este proceso se ve intermediado por la vinculación entre hombre máquina-herramienta; producto de ello, se producen mediaciones nuevas con alto nivel de desconexión, inclusive, hasta hacerlos antagonizar, en tanto especie y naturaleza. Es decir, el hombre deja de tocar y sentir la tierra, de sacar la leche, de criar animales, para mover a una máquina que haga ese trabajo por él. Esto facilita algunas bases culturales y epistemológicas que divorcian a las sociedades de las naturalezas, conformándolas de igual manera para los efectos epistémicos. Ello trae consigo nuevas conceptualizaciones de las 
naturalezas, de formas de conocer y con esto una crisis ecosocial.

\section{LA MODERNIDAD Y LA RELACIÓN HOMBRE-NATURALEZA (CAPITALISMO-EPISTEMOLOGÍA)}

Esta nueva cultura de relaciones sociales mercantiles va a cambiar a las anteriores que favorecen el animismo, la identidad y pertenencia, con lo cual cambia también la definición del sujeto a conocer, el objeto y la manera de hacerlo. Es decir, quién conoce, qué y el cómo, no son respuestas que se deban buscar ahistóricamente; por el contrario, requieren de los contextos históricos que determinen la imagen de realidad, pues desde ella surgen estas preguntas y respuestas.

Cuando hacemos referencia al mundo griego, pocas veces nos preguntamos por la conexión que existe entre la imagen de realidad -como el supuesto que permite convivir con una naturaleza posible, aquella voluntad devenida dioses- y el cómo la conocen, es decir, un ámbito relacional entre sujeto-sujeto. Por ello, ni Penélope ni el pueblo de Ítaca dudaron de una historia, que para nuestro siglo sería irrisoria, pues el enojo de Poseidón era una respuesta más plausible que los vientos y las mareas como simple fenómeno natural.

En esta nueva época, e inicios del capitalismo, la naturaleza deja de representar un sujeto, por ende, ya no se corresponde una necesidad colaborativa con ella. Esta la va alejando de todo animismo, ya no se necesita una buena relación para que esta provea una buena cosecha. Al ser la máquina la que lo haga, se desarrolla una tecnología con la misión de construirla y mejorarla; en consecuencia, para lograrlo, hay que atender a una revolución de tipo racionalista, apoyada en el ideal matemático de realidad. Kedrov (1990), lo denomina una revolución copernicana, porque eleva el pensamiento abstracto por sobre el común. ${ }^{9}$ En última instancia, la necesidad de mejorar -la máquina y tecnologíaobliga a validar un nuevo pensamiento, uno que intenta favorecer Galileo cuando escribe que la naturaleza está escrita en lenguaje matemático, con los legalismos que le dan sentido.

A nivel de la teoría del conocimiento, la naturaleza pasó a ser susceptible de ser conocida a través de la razón y de un método que la ordena, desprovista de todo animismo que la subjetiva. El descubrimiento ocupa una manera de describir el proceso en el cual un sujeto distinto del objeto lo conoce por la revelación que éste hace a aquel; en otros términos, el sujeto se va a acercar a otro, quien se le exhibe gracias a la interrogación que le hace el método científico. El invento también adquiere notoriedad en la afirmación del sujeto. Todo ello en coherencia con una naturaleza que pasó a ser naturalizada como un abstracto externo, un no-yo. Con ello, el conocimiento se posesiona como problema filosófico durante gran parte de la modernidad, y no es algo banal para comprender la actual crisis ecosocial. 
Algunas constantes de cambios epistemológicos y su impacto en la crisis ecosocial:

a) La relación epistemológica sujeto y objeto de conocimiento no sucede de manera distinta a la dualidad sociedades-naturalezas (yo, no-yo), de la producción cultural moderna, como lo atestigua Bacon (1998, p. 8), al señalar, "La historia o es natural o civil. En la historia natural se refieren los hechos de la naturaleza, en tanto que en la historia civil lo son los de los hombres". Lo que en el mismo sentido se sigue con Descartes, al diferenciar la res cogitans, como la cosa que piensa -matemáticamente- y como una sustancia esencialmente distinta de la res extensa, o cosa extensa, que incluiría a la naturaleza como lo corporal-máquina. En ambos autores está presente la idea de dominio y manipulación del hombre hacia la naturaleza, dado que sintetizan una época que la convierte en un objeto desprovisto de vida, valor y belleza, posible de ser triturable y cosificada como mercancía, y garantizar así una nueva base productiva.

Esta escisión adopta diversas formas y sirve para las modernas fundamentaciones según los ámbitos de reflexión; desde la Filosofía política, Montesquieu, en términos generales, plantea una historia humana que evoluciona y, por otro lado, fenómenos naturales que permanecen invariables, como dualidad para argumentar su propuesta política y diferencias entre leyes positivas y naturales; los contractualistas, por su parte, distinguen entre la voluntad como artificialidad del mundo humano y un estado natural. En la Ilustración, se acentúa la separación hombre racional y mundo natural dominado, según el ideal del progreso e interés en los cambios económicos y culturales de la época, manteniendo la misma desconexión entre la historia natural y social.

b) En cuanto a este objeto de conocimiento, comenzó a perder lo vital del modelo aristotélico organicista y pasó a ser más cercano a la metáfora de máquina. Es el mecanicismo lo que permite hacer algunas reducciones. Galileo excluye la cualidad de la ciencia, restringiéndola a los fenómenos cuantitativos; Descartes, en su lógica, crea un método coherente que permite desmenuzar los fenómenos en partes para comprender las propiedades de estas y así el funcionamiento de todo. $Y$ finalmente, esta gran máquina divisible, perfecta, gobernada por leyes, fue triunfalmente completada por Newton. Ello se va expandiendo a las distintas disciplinas; por ejemplo, la Biología lo reconoce en el modelo de circulación sanguínea (Capra, 1998).

Este objeto-máquina, además, fue cumpliendo con el determinismo causal al ser descrito a través de leyes, las cuales presuponen comportamientos uniformes y constantes del objeto, con un grado de universalidad y necesariedad. La voluntad de los dioses dejó de estar presente, pues de alguna manera arriesga toda la regularidad e inmutabilidad para que puedan cumplirse la ley natural y todas las certezas modernas.

c) En cuanto al sujeto, éste pasó a ser definido como un individuo racional, configurándose como un otro que observa neutralmente 
este movimiento permanente e inmodificable del objeto. $Y$ con ello, la diferencia entre ambos se desprende de la exclusión del valor de la cognición, triunfando la objetividad del saber ${ }^{10}$ y lo que hoy cuestiona la Bioética, como veremos más adelante.

d) El saber científico ocupó un lugar privilegiado de supremacía por sobre otros, lo que jerárquicamente no había sucedido con tal fuerza; los otros saberes fueron desplazados en su validez; lo fue el saber común, religioso y mágico.

En cuanto a la organización del conocimiento científico, éste se dividió en distintas disciplinas y especialidades. Vitale describe la diversificación señalando que "Desde el momento en que la ciencia comienza a ser el motor de los principales avances técnicos para el crecimiento industrial, se fragmentó en tantas especialidades como requería el proceso productivo" (1998, p. 1). Algo de razón tiene cuando se relaciona el saber científico y la manufactura.

Además, los objetos de estudios se fueron divorciando como trama social-natural y estableciendo el cisma de dos culturas científicas, las ciencias duras y blandas, con sus distintas comunidades científicas, y con el fundamento teórico de clasificaciones como las de Dilthey, que separa las ciencias de la naturaleza del espíritu, entre otras. Con el apoyo de las bases dualistas cartesianas de disyunción sujeto-objeto, se plantea el mundo de los objetos, comprensible al conocimiento objetivo y científico, y, por otro lado, el de los sujetos, favoreciendo la división del conocimiento en ciencias duras objetivas, como la Física, Astronomía, Biología, y ciencias blandas reflexivas y sociales.

Posteriormente, las ciencias sociales pretenden acreditarse al alero de la legitimidad de las ciencias naturales -como lo detalla muy bien la investigación realizada por la Comisión Gulbenkian (Wallerstein, 1996)-. Su adscripción, desde el siglo XIX, al método científico implicó representar el objeto social de estudio de acuerdo a imagen y semejanza de esta nueva realidad natural. Lo que para entonces significaba no solo la búsqueda de cientificidad a sus propuestas, sino además revalidar los presupuestos que tuvo el saber científico en sus orígenes; la existencia de un objeto que fuera simple, regular y constante, manipulable, determinable y, por cierto, puesto de manera independiente del sujeto, quien, obviamente, es distinto de aquel; pero además, neutro, objetivo, desprendido de valoración por parte del investigador.

La influencia de esta orientación se manifestó, inclusive, en la definición de los objetos de estudios y nomenclaturas derivadas de la expectativa de las ciencias duras, como objetos de estudios, aparentemente, objetivables como la conducta en Psicología posesionada con el conductismo de Watson y posteriormente de Skinner; en el Derecho, la autonomía neutral de la norma jurídica, bajo los influjos de la Teoría Pura del Derecho de Kelsen (1994); en Sociología, el hecho social como "física social"; la Criminología positivista con pretensiones 
etiológicas que participan del análisis causal-explicativo (GarcíaPablos, 2007). La Historia como disciplina, desde Ranke, Niebuhr y Droysen, se orientó hacia la reconstrucción de la realidad pasada -de manera objetiva con fuentes primarias-. La Antropología no hizo nada distinto con los modos de organización y con las distintas costumbres sociales.

En definitiva, esto significó fundar modelos explicativos y admitir realidades que tuvieran una esencia de inmutabilidad y que, a la vez, permitieran buscar causas o sometimiento a legalismos; es el punto de inflexión más claro de la dualidad sociedad-yo y naturaleza no-yo. Esto irá cambiando desde el siglo XX, el cual abrirá paso a grandes revoluciones científicas, desafiadas no solo por las ideas, sino, principalmente, por las crisis ecosociales.

\section{LA CRISIS ECOSOCIAL Y UNA EPISTEMOLOGÍA EMERGENTE}

La época actual exige la solución permanente de problemas amenazantes, los que a su vez conllevan la visualización de otros, y de ello, el problema ecológico es uno de los principales exponentes. Una de las primeras estrategias de intervención a la crisis ecosocial, bajo el alero de un paradigma mecanicista, se intentó resolver dada la imagen científica de la máquina fraccionable con una solución específica, es decir, descontaminando un río, restringiendo los niveles de consumo de algún recurso, y otros de acuerdo a la necesidad concreta de un colectivo interesado. Todo lo cual, realizado bajo los límites explicativos del reduccionismo, de la dualidad cartesiana, del atomismo y bajo el alero de una disciplina particular, como la Biología, Zoología, e incluso la Jurídica.

Pero poco a poco aparecieron nuevos y conectados problemas que ponen en duda tal perspectiva, lo que ocasionó el surgimiento de nuevas metodologías, enfoques y pensamientos relacionales, como la Teoría General de Sistemas, los Pensamientos sistémicos y complejos. Con ello se comienza a entrelazar la relación sociedades-naturalezas, de manera de ir conformando un modelo epistemológico cada vez más considerativo de ambos, y cuestionado su estudio por separado; tanto desde las metodologías, como desde la propia institucionalización organizativa del saber y sus comunidades científicas. Un ejemplo de esto lo encontramos en el proceso e informe denominado "Los límites al crecimiento", realizado por el Club de Roma. ${ }^{11}$ Una de las características de éste, que lo hacen notable y paradigmático, es su peculiaridad de planteamientos e interpretaciones como perspectiva global, no solo con el objetivo de dejar al descubierto la gravedad del problema ecológico, sino que además lo obtiene por la novedad del procedimiento. Sus resultados provienen de su multidisciplinaria composición y su metodología interdisciplinaria, conceptuado como alternativa histórica para comprender el problema que se configurará con extensiones globales y holistas. ${ }^{12}$ 
En definitiva, se asomaba una crisis ecosocial desbordante del control científico y de sus paradigmas clásicos de conocimientos, los cuales han debido aceptar su incapacidad para dar respuesta a los requerimientos complejos actuales, que demandan cambios y revoluciones epistemológicas, e incluso, de la propia racionalidad clásica.

Lo anterior, favorece en ámbitos epistemológicos la crisis hacia: a) ciertas constantes de la racionalidad científica -relación epistemológica sujeto y objeto de conocimiento, el mecanicismo y su método-; b) a la dificultad de mantener las fronteras entre lo natural y lo social, y su institucionalización como saber científico, dividido en ciencias naturales y sociales; c) a la pérdida de jerarquía excluyente de este saber respecto de otros, lo que le vale aceptar el común, mágico o mítico; d) además de poner en duda el prototipo de genio científico para comenzar a mirar el desenvolvimiento de comunidades científicas interesadas.

\section{a) Rupturas de ciertas constantes de la racionalidad científica}

Los distintos ámbitos científicos se ven demandados por sus problemas científicos y no encuentran respuestas en sus modelos tradicionales. Así, por ejemplo, la Física, con su concepción cuántica, reconoce que las partículas subatómicas carecen de significado como entidades aisladas del todo, lo que ha propiciado el abandono de la idea del mundo compuesto por entidades discretas o de ladrillos newtonianos y sus linealidades. A lo que se le suma la Teoría de la Relatividad de Einstein, la dualidad onda partícula, y el principio de incertidumbre de Heisenberg. En el ámbito de la Psicología, la caja negra, como se le denominó a la mente, irrumpe ante la insuficiente simplicidad del estudio de la conducta que consolidó la Psicología positivista, para ir complejizando con el constructivismo, o con teorías como la Gestalt, al sostener que el todo es más que la suma de las partes en la comprensión del funcionamiento mental. Por otro lado, la Ecología como disciplina, desde Haeckel, aporta a los cambios con el estudio de la relación de los seres vivos, sus hábitats, y con ello contribuye a las significaciones de redes, comunidad y sistemas vivos; está la noción de Biosfera, acreditada por el geólogo ruso Vernadsky, y la de Hipótesis Gaia, con la cual Lovelock y Margulis, afirman que la tierra está viva y que tiene un comportamiento autorregulado, oponiéndose a la concepción clásica de una tierra inerte e inorgánica de elementos inanimados, con leyes matemáticas de movimiento, que principalmente se habían construido desde la modernidad. Gaia representa el conjunto de toda la vida en la tierra como un único organismo relacionado desde las bacterias a los elefantes, tan interdependientes como las células de nuestro cuerpo. En la Biología molecular se correlaciona el todo y la parte sistémicamente, la autopoiesis de Maturana y Varela que señalan que toda la red viva se hace a sí misma, con las contribuciones de nociones como las de autorregulación del sistema vivo. La Cibernética y el aporte para conocer los patrones de comunicación, y las estructuras disipativas de llya Prigogine, entre algunos. 
Los anteriores ejemplos nos permiten señalar que la ciencia participa como un eslabón en la cadena de las contraposiciones del hombre y la naturaleza, y de cómo se organiza de acuerdo a las bases culturales para sus conocimientos. Bien lo dice Heisenberg:

[...] no le es lícito hablar sin más de naturaleza 'en sí' [...] La ciencia natural presupone siempre al hombre, y no nos es permitido olvidar que, según ha dicho Bohr, nunca somos sólo espectadores, sino siempre también actores en la comedia de la vida. (1976, pp. 12-13)

La dificultad de mantener fronteras entre lo natural y lo social, como lo mantuvo la institucionalización del saber científico que lo ha dividido en ciencias naturales y sociales, ha sido una consecuencia conjunta de lo anterior, pues los distintos ámbitos que fueron invadiéndose mutuamente también fueron avanzando hacia el reconocimiento de la complejidad como atributo de la realidad en sus dimensiones ontológicas y epistemológicas.

Las nuevas consideraciones comienzan a concebir a los sistemas complejos, como aquellos compuestos por componentes interrelacionados por procesos emergentes, hechos $\mathrm{u}$ objetos multidimensionales, interactivos, con un grado de aleatoriedad, azar e indeterminación; comienzan a propiciar nuevos paradigmas y consensos en las distintas comunidades científicas, las cuales van a sincronizar con un paradigma abarcador denominado por algunos complejidad o complejidades -dado que no es una sola como advierte Maldonado (1999)-. Entre quienes lo han impulsado desde distintas perspectivas están Sotolongo y Delgado (2006); con la nueva física, el tao de la física de Fritjof Capra (2003), o como un paradigma emergente entendido como conocimiento prudente para una vida decente, según De Sousa Santos (2009); o bien con Morin (2003) y la Cátedra itinerante de la UNESCO dedicada a la formación en Pensamiento Complejo y Epistemología Compleja; la Cátedra para el estudio de la complejidad propiciado por el Instituto de Filosofía de La Habana de Cuba, dedicado a temas relacionados con la complejidad y sus implicaciones teóricas, epistemológicas y metodológicas, solo a modo de ilustración.

Desde ahí, ni las sociedades, ni las naturalezas, pueden afirmarse de manera mecanicista, ni son posibles de ser estudiadas bajo el estereotipo de modelos científico-clásicos, sin asumir estas nuevas consideraciones a la complejidad, que como criterio general implican ruptura.

En definitiva, lo que comenzó a ser revolucionado desde ámbitos disciplinarios, hoy es compartido bajo un lenguaje científico común. Una relación sociedades-naturalezas en crisis ha transformado el conocimiento científico, no solo para conocerla, pues a diferencia del ideal moderno de manipulación antropocéntrico que lo hizo para dominarla y servirse de ella, hoy se requiere para sobrevivir. Esto es fundamental para diferenciar 
y validar la relación determinante e inmanente, entre crisis ecosocial y cambios epistemológicos.

\section{b) La insuficiencia de las divisiones disciplinarias}

La evolución de estas ideas se ha masificado como una necesidad de reflexiones en las comunidades científicas. Como parte de este movimiento, se convoca al "Primer Congreso Mundial de Transdisciplinariedad", en el cual los participantes adscriben a un documento que se publicitó como "la "Carta de la Transdisciplinariedad", y que en uno de sus principios manifiesta: "Sólo una inteligencia que dé cuenta de la dimensión planetaria de los conflictos actuales podrá hacer frente a la complejidad de nuestro mundo y al desafío contemporáneo de la autodestrucción material y espiritual de nuestra especie"13. La negación al reduccionismo, al pensamiento que mantiene la existencia de la mónada como metáfora de la realidad individual, es un elemento que está presente en un primer momento de la conciencia ecológica y en el sentido de la ruptura epistemológica.

Desde el aporte de la conciencia social ecológica, podemos ver la orientación que adquiere la imagen de la realidad, cada vez más multidimensional; necesitando de nuevos encuentros disciplinarios para abordarla. Se requieren desde tal desafío, la relación de disciplinas, y los aportes mutuos de sus saberes, desde la Estadística, Cibernética, Teoría de Sistemas, Física Nuclear, Bioquímica, Biología, Oceanografía, Termodinámica. ${ }^{14}$ Ello demanda la necesidad de unir disciplinas, enfoques, como la Ética Ambiental, que se basa en aportes de la Ecología, al igual que el nuevo paradigma (NEP, New Exceptionalism Paradigm) "capaz de considerar de una vez, efectivamente, la influencia recíproca ineluctable, entre leyes ecológicas y regulaciones políticas, económicas y sociales" (Padres, 1997, p. 17).

En definitiva, el movimiento de la conciencia ecológica evoluciona hacia una visión totalizante socio-natural. Con cada vez menos ámbitos desconectados en parcialidades, con lo cual produce una nueva forma del ser consciente, nuevo conocer y saber científico. Esta evolución ha revolucionado la perspectiva de la comunidad científica, la mantiene centrada en desafíos de tal envergadura, que se encuentra no solo en mejoramiento de teorías de interrelación, como la Teoría General de Sistemas, ni Cibernética, o la Teoría de la Comunicación, sino también en la búsqueda de una teoría científica de la totalidad unificada. Stephen Hawking, uno de los investigadores actuales de mayor prestigio en el análisis de la totalidad, se pregunta por la "unificación de la física", y se pronuncia por la búsqueda de una teoría que incluya todas las teorías parciales que conocemos, sin perjuicio de su carácter relativo (Hawking, 1998, pp. 224-225) y lo que ha impulsado el sentido del holismo.

En definitiva, los nuevos paradigmas científicos de la complejidad provenientes de la realidad socionatural y su tendencia incluyente se manifiestan en cambios epistemológicos que abarcan momentos de cambios institucionalizados, como lo son las organizaciones del saber científico de acuerdo a objetos de 
estudios, denominados naturales o sociales. Lo que de alguna forma, a partir de la complejidad de la relación socionatural, se acerca a tendencias multidisciplinarias, interdisciplinarias e incluso transdisciplinarias. Además de las relaciones a nivel de redes, procesos y conexión de sistemas complejos con fronteras difusas.

c) El riesgo de las Generaciones Futuras nos ha producido una conciencia de especie, que nos formula la pertenencia a una categoría superior, hacia la objetivación de la relación naturaleza humana-no humana y que la conciencia ecológica encarna con la unidad de yo-no yo (Gómez, 2007).

Al mismo tiempo, la pérdida de jerarquía excluyente de este saber respecto de otros le vale aceptar el común, mágico, mítico de las sabidurías ancestrales, como es el caso, por ejemplo, de las medicinas tradicionales, las que han sabido ir recuperando un lugar que el saber científico les había despojado.

En algunos niveles, las comunidades científicas, como productoras de conocimiento, han ido perdiendo credibilidad y con ello el saber que portan. La Bioética, tanto en su visión aplicada como la global potteriana, ha dado una voz de alerta a esta amenaza.

Especial mención merece el surgimiento de la Bioética. El término y propuesta es un legado de Van Rensselaer Potter, ${ }^{15}$ como también su reflexión, que promueve la necesidad de crear un puente hacia el futuro que comunique a las dos culturas hasta ahora disociadas, las ciencias y humanidades, erigiendo para ello a la disciplina de la Bioética-. Este autor fue uno de los primeros que denotaron, en la década del setenta del siglo pasado, la urgente necesidad que tiene la humanidad de la existencia de un saber que le proporcione conocimiento inclusivo de lo cognitivo y valorativo, y del cómo usar los nuevos avances científico-tecnológicos en las relaciones vida-muerte, naturaleza, universo-ciencia, tecnología.

Se plantea, incluso, a la Bioética como un nuevo saber (Fung, 2002) y entre los argumentos que figuran para caracterizarla está la incorporación del valor a la cognición que niega la dualidad establecida desde la modernidad, principalmente por Kant, quien proyecta la separación entre el ámbito del conocimiento y el de la voluntad (Sotolongo, 2002); su pretensión de totalidad como saber omnicomprensivo con capacidad heurística a la transdisciplina como unidad de perspectiva entre lo científico y humanista, negando así las clásicas independencias entre lo social y natural. El desafío lo enfrenta a una nueva reflexión sobre la ciencia y la tecnología, la vida, el ambiente, la organización social, conductual, reflexiva-valorativa.

d) La comunidad científica, como portadora de la conciencia ecológica desde una faz cognitiva, es decir, como un grupo capaz de proporcionar un nivel sistematizado de organización de los elementos informativos, a niveles de teoría y empiria, pertenece a una sociedad civil a la que se le exige ser 
autoconsciente de la importancia que representa su participación en la etapa de crisis ambiental. Además, se le reconoce su papel educativo divulgador del cambio de patrones contaminantes, y más específicamente su significativo aporte a la mediación de las políticas públicas, como analiza Delgado. ${ }^{16}$

Además de poner en duda el prototipo de genio científico para comenzar a mirar el desenvolvimiento social y de poder de las comunidades científicas lo plantea desde fines del siglo XX, con autores como Lakatos (1993), Feyerabend (1998) y Kuhn (1998).

En definitiva, la relación sociedades-naturalezas demanda una lectura de crisis para teorizar sobre ella y transformar lo que se requiera para sobrevivir.

\section{UNA REFLEXIÓN FINAL Y CONCLUSIÓN}

1) Ni la Filosofía ni la Epistemología, en particular, deben obviar el desafío de nuestra historia actual, donde los humanos y no humanos están en permanente relación con el dolor y el riesgo de no sobrevivir. En consecuencia, desde las Generaciones Futuras se nos exige un compromiso militante con las reflexiones que se pretenden validar como fuente de conocimiento y base de decisiones.

2) La práctica social actual está determinada por la crisis ecosocial, lo que no solo nos advierte contradicción, sino, al mismo tiempo, un estadio histórico que dificulta la separación, en todos los niveles, de la relación sociedades-naturalezas. En otros términos, las dimensiones sociales, al ser concebidas como categorías, es decir, al representar la actualidad de la interacción real del sujeto y objeto histórico, no pueden obviar la indivisibilidad de la relación sociedades-naturalezas como fundamento de configuración de realidad e interacción en ella desde los saberes hegemónicos, especialmente el científico.

3) Los contextos históricos culturales dan cuenta de una coherencia que se produce entre una imagen de realidad, que abarca la relación sociedades-naturalezas y las formas de conocerlas.

4) Los inicios del capitalismo nos legaron una epistemología histórica y con ella una manera de concebir la realidad. Una relación sociedades-naturalezas, donde la naturaleza se transformó en una máquina descomponible, regular y constante; el sujeto en un racional, neutro y distinto de la naturaleza y un contexto favorable como ideal de manipulación y dominación del segundo a la primera. Todo lo cual coadyuvó al estado actual de crisis ecosocial y a la insuficiencia y límites de sus soluciones.

5) La crisis ecosocial porta la contradicción de una relación específica, o sea, de un tipo de sociedad-naturaleza; y con ello, la insuficiencia del conocimiento científico simplificador, tanto de 
sus paradigmas reduccionistas como de la eliminación del valor de los procesos cognitivos y la producción del conocimiento científico.

6) La validez y legitimidad de los cambios epistemológicos deben ser coherentes con los tiempos presentes y futuros. Porque para poder actuar en nuestra obra, debemos validar que somos actores principales, tanto como la naturaleza, sin la cual no podríamos respirar futuro. Conocer esta trama exige una epistemología compleja.

\section{REFERENCIAS}

- Abbagnano, N. (1955). Historia de la filosofía (T. I.). Cuba: Estudios Instituto del Libro.

- Ángel-Lara, M. A. (2003). Reflexiones sobre el devenir de la subjetividad: pretextos presocráticos. Parte II. Revista Ciencia y Mar, 7(21), 3-17. Recuperado de http://www.umar.mx/revistas/22/presocraticos.pdf

- Bacon, F. (1998). Teoría del cielo. Barcelona: Ediciones Altaya.

- Barros, C. (1997). La humanización de la naturaleza en la Edad Media. Congreso Mensch und Natur im Mittelalterlichen, Europa, organizado por la Academia Friesach (Universidad de Klagenfurt, Austria), 1-5 de septiembre de 1997. Recuperado de http://www.h-

debate.com/cbarros/spanish/humanizacion_castellano.htm

- Burlatski, F. M., et al. (1982). Materialismo histórico. Moscú: Editorial Progreso.

- Capra, F. (1998). La trama de la vida: una nueva perspectiva de los sistemas vivos. Barcelona: Anagrama.

- Capra, F. (2003). El Tao de la física. Málaga: Editorial Sirio.

- Delgado, C. (1996). El papel de la comunidad científica en la formación de la política pública del medio ambiente en Cuba. En Ecología y Sociedad. La Habana: Estudios, Editorial CENIC.

- Delgado, C. (2002). Límites socioculturales de la educación ambiental. México: Editorial Siglo XXI.

- De Sousa, B. (2009). Una epistemología del Sur: la reinvención del conocimiento y la emancipación social. México: Siglo XXI y CLACSO.

- Donini, A. (1961). Historia de las religiones. Buenos Aires: Editorial Futuro.

- Feyerabend, P. (1998). Adiós a la razón. Barcelona: Altaya.

- Fung, T. (2002). La bioética: ¿Un nuevo tipo de saber? En Bioética para la sustentabilidad. La Habana: Publicaciones Acuario, Centro Félix Varela.

- García-Pablos, A. (2007). Criminología: una introducción a sus fundamentos teóricos. Valencia: Tirant lo Blanch.

- Gómez, T. (2007). La conciencia ecológica: una nueva forma de la conciencia social. Tesis de Doctor en Ciencias Filosóficas, no publicada. Universidad de La Habana, La Habana.

- Hawking, S. (1998). Historia del tiempo: del Big Bang a los agujeros negros. Barcelona: Grijalbo. 
- Heisenberg, W. (1976). La imagen de la naturaleza en la física actual. Barcelona: Editorial Ariel.

- Kedrov, B. (1990). Lenin y las revoluciones científicas. La Habana: Editorial de Ciencias Sociales.

- Kelsen, H. (1994). Teoría pura del Derecho. Buenos Aires: EUDEBA.

- Kuhn, T. (1998). La estructura de las revoluciones científicas. México: Fondo de Cultura Económica.

- Lakatos, I. (1993). La metodología de los programas de investigación científica. Madrid: Alianza Universidad.

- Maldonado, C. (1999).Visiones sobre la complejidad. Colombia: Ediciones El Bosque.

- Malinowski, B. (1998). Estudios de psicología primitiva. Barcelona: Ediciones Altaya.

- Milton, K. (1997). Ecologías: antropología, cultura y entorno. Recuperado de http://www.unesco.org/issj/rics154/miltonspa.html

- Morin, E. (2003). Introducción al pensamiento complejo. España: Gedisa.

- Padres, J. (1997). Sociología y medio ambiente. En Jesús Ballesteros, J. y Pérez Adán, J. (Eds.). Sociedad y medio ambiente. Madrid: Editorial Trotta.

- Programa de las Naciones Unidas para el Medio Ambiente. (2011). Seguimiento a nuestro medio ambiente en transformación: de Río a Río+20 (1992-2012). Recuperado de http://www.unep.org/geo/pdfs/Keeping_Track_es.pdf

- Sotolongo, P. L. (2002). Bioética y contemporaneidad. Acerca de algunos fundamentos cosmovisivos y epistemológicos de la bioética. En Bioética para la sustentabilidad. La Habana: Publicaciones Acuario, Centro Félix Varela.

- Sotolongo, P. L. y Delgado, C. (2006). La revolución contemporánea del saber y la complejidad social: hacia unas ciencias sociales de nuevo tipo. Recuperado de http://bibliotecavirtual.clacso.org.ar/ar/libros/campus/soto/sot o.html

- UNICEF. (2012). Mi hijo ya no come arena. Recuperado de http://www.unicef.es/actualidaddocumentacion/publicaciones/mi-hijo-ya-no-come-arena

- Vitale, L. (1998). El tiempo en la relación sociedad-naturalezaambiente. Recuperado de http://www.nodo50.org/ciencia_popular/articulos/Vitale.htm

- Wallerstein, I. (Coord.). (1996). Abrir las ciencias sociales. Informe de la Comisión Gulbenkian para la reestructuración de las ciencias sociales. México: Siglo XXI.

1. Abogada y Doctora en Ciencias Filosóficas de la Universidad de La Habana. Académica de la Universidad de Atacama de Chile (Av. Copayapu 485, Facultad de Ciencias Jurídicas, Copiapó III Región Chile). Docente investigadora en el área de Filosofía del Derecho.taeli.gomez@uda.cl

2. Por lo tanto, utilizamos la noción de ecosocial como un término que nos propusimos para integrar la relación sociedadesnaturalezas en una sola crisis, pero además para enfatizar la contradicción, no solo las consecuencias. 
3. Aludimos en plural a ambos conceptos, en primer lugar, para enfatizar el carácter histórico de la significación de la relación; por lo tanto, sin absolutez universal, ni invariabilidad, como relación sociedad y/o naturaleza. Y en segundo, las unimos a través de plecas, para afirmar que sus definiciones surgen desde la relación, y no son previas a ellas. Bien señala el Nobel Heisenberg (1976), cuando afirma que la imagen no es la de naturaleza, sino de nuestra relación con ella.

4. Este aparente contrasentido lo resuelve Luis Borges, cuando dice que son los sucesores quienes crean a los precursores. De ahí, entonces, indagar la relación que pueda haber entre esta relación y la teoría del conocimiento obedece a la necesidad de explicar los contextos críticos actuales; por tal razón, siempre las búsquedas en el pasado obedecen a intereses desde el presente. En otros términos, el riesgo de nuestra especie nos exige comprender la importancia de momentos mediatorios que permitan identificar interrelaciones no previstas y que no se lograrían, sin esta espada de Damocles que pende sobre las arrogancias humanas.

5. Entre algunos autores que tratan estas perspectivas generales están Kedrov (1990) y Kuhn (1998).

6. Pero no como algo inventado, según lo explica Malinowski, no fue creada, sino como un "añadido esencial a todas aquellas cosas y procesos que interesan vitalmente al hombre, pero que resisten sus esfuerzos racionales (Malinowski, 1998, p. 71).

7. Hay ejemplos que señalan cómo los cazadores interaccionan con sus presas partiendo de una confianza mutua, mientras que los pastores controlan las vidas de sus animales robándoles la autonomía sobre la cual se construye la confianza. Así, mientras los cazadores consideran a los animales seres del mismo tipo que ellos, los ganaderos probablemente consideran a los animales como objetos de dominio humano (Milton, 1997).

8. El debate es intenso y el saber religioso está por sobre los demás. En este contexto se explica que la naturaleza tiene de sagrado lo activo de su movimiento; sin embargo, éste no es inmanente como se dirá posteriormente, con los panteístas como Giordano Bruno, para el cual Dios es una causa interna a los fenómenos de la naturaleza, o como Spinoza, para quien la sustancia infinita es equivalente a Dios o la naturaleza (Deus sive natura), sin una trascendencia divina. De ahí la coherencia heliocéntrica del universo, donde la tierra tampoco ocupa posición privilegiada.

9. Pues bien, a quién se le cree, a quien ve el sol moverse o a quien lo dice matemáticamente y lo hace coherente a través de leyes con un método científico.

10. Lo que llega a la cúspide con Kant y su diferencia entre razón pura y razón práctica.

11. En Roma, con fecha 1968, académicos, científicos, investigadores y políticos de 30 países se reúnen para debatir por las modificaciones del entorno ambiental que están afectando a la sociedad. Posteriormente, se formalizarán como asociación bajo la legislación de Suiza.

12. Este utiliza los trabajos realizados en el System Dynamics Laboratory del Instituto de Tecnología de Massachusetts (Massachusetts Institute of Technology: MIT). Estos fueron liderados por Forrester, aplicando el modelo de la Teoría de Sistemas. Se aplicó a diseños computacionales que simulan 
escenarios posibles para el futuro de la humanidad. Para conformarla se consideraron algunas variables, tales como el monto y tasa de incremento de población, disponibilidad y tasa de utilización de los recursos naturales, crecimiento del capital y la producción industriales, producción de alimentos y extensión de la contaminación ambiental, se interrelacionaron con ese objetivo. Este paradigma sistémico utilizado comparte una época de enfoques similares que, en conjunto, advierten la insuficiencia histórica de una perspectiva unidimensional de una racionalidad científica fragmentaria para comprender la realidad compleja emergente con una perspectiva holista.

13. El Primer Congreso Mundial de Transdisciplinariedad (Convento de Arrábida, Portugal, noviembre, 2 a 7 de 1994) adopta un conjunto de principios fundamentales, entre los que se encuentran los de Morin.

14. Por ejemplificar, las leyes de la termodinámica se utilizan en la economía, y otros como la Psicología Ambiental, que representa una fusión multidisciplinaria de la Arquitectura, la Sociología, la Antropología, la Economía y las psicologías Colectiva, Social, Política, Educativas.

15. Este autor, bioquímico de Wisconsin, es quien por primera vez utiliza el término de Bioética al publicar en 1970 el artículo "Bioethics. The Science of Survival" en la revista Perspectives in Biology and Medicine, no obstante, como lo recuerda José Ramón Acosta, en el libro Bioética para la sustentabilidad, es en 1971, con el libro Bioethics to the Future, que efectivamente trascendió dicho término.

16. "1) por sus conocimientos y potencialidad técnica, 2) por la dimensión actual de las soluciones globales al problema, 3) por la significación cultural de prestigio de la comunidad científica como tal, y 4) por la existencia de vías estatales y no estatales para acceder a la formulación de las políticas que tiene este grupo social" (Delgado, 1996, p. 75).

Para citar este artículo: Gómez Francisco, T. R. (2015). La crisis medioambiental y su impacto como epistemología compleja. Revista Luna Azul, 41, 254-273. Recuperado de http://lunazul.ucaldas.edu.co/index.php?option=content\&tas k=view\&id=1065 